\title{
LAS ELECCIONES DOMINICANAS DE 1994 El último clivaje de una cuasipoliarquía gerontocrática y delegativa
}

\author{
Jacqueline Jiménez Polanco*
}

El 16 de mayo de 1994 tuvieron lugar en la República Dominicana las quintas elecciones generales ordinarias (presidenciales, congresuales y municipales) celebradas en este país caribeño desde la recuperación poliárquica de 1978 y las novenas elecciones nacionales competitivas o casi competitivas de su reciente historia política, desde que en 1962 se produjera el primer paso del antipartidismo al pluralismo de partidos tras el asesinato de Rafael Trujillo (1961).

En la elección presidencial resultó ganador Joaquín Balaguer (1.275.460 votos) por el PRSC y aliados frente a José Francisco Peña Gómez (1.253.279 votos) por el PRD y aliados. A nivel congresual la coalición encabezada por el PRSC obtuvo 14 escaños en el Senado y 50 en la Cámara de Diputados, la del PRD 15 escaños en el Senado y 57 en la Cámara de Diputados, y la coalición encabezada por el PLD 1 curul en el Senado y 13 en la Cámara de Diputados. A nivel municipal, la composición de los Ayuntamientos municipales quedó dividida en 58 sindicaturas (alcaldes y suplentes) y 294 regidores para el PRSC y aliados, 49 sindicaturas y 287 regidores para el PRD y aliados, 61 regidores para el PLD y aliados, y 4 regidores para el PRI.

Las elecciones en la República Dominicana han sido siempre muy conflictivas. Un análisis de los comicios de 1994 requiere, a mi juicio, la observación de tres factores sin cuya comprensión resulta difícil desgajar los elementos de la endémica crisis política producida por (y en) cada uno de los procesos electorales que se han celebrado desde 1978, fruto de los rasgos propios de una transición poliárquica que a 17 años de su última recuperación sigue preservando la incerteza e impredecibilidad de su naturaleza híbrida: autoritaria y democrática, y que, a pesar de los cambios surgidos a raíz de su último clivaje, parece anunciar todavía un lento y difícil camino hacia la consolidación democrática.

(*) Coordinadora del Seminario "Los Sistemas Políticos en el Caribe", Centro de Estudios Contemporáneos sobre América Latina (CECAL): Universidad Complutense de Madrid y profesora de la Maestría de Estudios Latinoamericanos del Instituto de Estudios de Iberoamérica y Portugal: Universidad de Salamanca. Investigadora del Proyecto Rockefeller "Caribe 2000" en la Universidad de Puerto Rico.
Tabla I

PROCESO ELECTORAL DE 1994.

CANDIDATURAS A CARGOS NACIONALES: PRESIDENTE Y VICEPRESIDENTE

\begin{tabular}{lr}
\hline Partidos políticos & N. ${ }^{0}$ votos \\
\hline Partido Reformista Social Cristiano (PRSC) & 1.263 .341 \\
Partido Revolucionario Dominicano (PRD) & 1.188 .394 \\
Partido de la Liberación Dominicana (PLD) & 395.653 \\
Partido Revolucionario Independiente (PRI) & 68.910 \\
Partido Unión Democrática (UD) & 53.990 \\
Movimiento Independencia Unidad y Cambio (MIUCA) & 22.548 \\
Partido Popular Cristiano (PPC) & 5.793 \\
Partido Quisqueyano Demócrata (PQD) & 5.416 \\
Bloque Institucional Social Demócrata (BIS) & 5.002 \\
Movimiento de Conciliación Nacional (MCN) & 2.529 \\
Partido Democrático Institucional (PDI) & 1.882 \\
Partido Renacentista Nacional (PRN) & 1.237 \\
Partido del Pueblo Dominicano (PPD) & 1.055 \\
TOTAL GENERAL & 3.015 .750 \\
\hline Atras
\end{tabular}

Alianzas: PRSC - PQD - PDI - PPD - MCN - PRN; PRD - PPC - UD - BIS PLD - FNP - ASD.

Fuente: Datos Oficiales de la Junta Central Electoral. Resultado del Cómputo Electoral Provisional (Form 19).

Gráfico 1

RESULTADOS ELECCIONES 1994

Miles

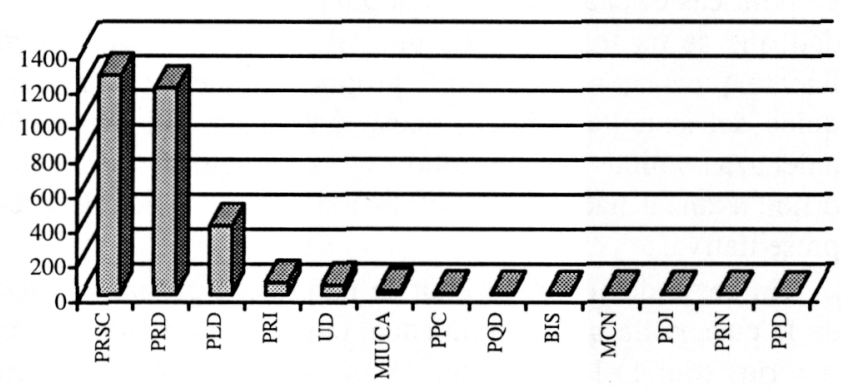

En primer lugar, definir el actual sistema político dominicano como una cuasipoliarquía, caracterizada por la fragilidad del sistema representativo y una práctica del debate público generalmente abierta y constante. Su fundamento se encuentra en las líneas de continuidad en la prácti- 
ca política e institucional democrática del autoritarismo, cuyos antecedentes en este siglo han sido la férrea dictadura trujillista (1930-1961) y la dictadura modernizadora de Balaguer (1966-1978). En el interregno, una profunda inestabilidad política provocada por un golpe militar contra Bosch (PRD) que frustró en 1963 la corta existencia del primer gobierno democrático de la historia republicana y provocó una segunda intervención militar de los Estados Unidos en 1965.

En efecto, las presiones políticas y sociales que impulsaron a finales de los años 70 la recuperación de la democracia, si bien promovieron una mayor inserción de la población en los mecanismos de participación, no promovieron una transformación social e institucional que condujese a la consolidación del sistema político en base a cuatro objetivos básicos: la construcción de un modelo de desarrollo social sostenido, el derecho a la libre participación política, la existencia de gobiernos responsables y la estabilidad de las reglas del juego democrático.

La política del eterno retorno, seguida por los gobiernos del PRD en plena oleada democrática (1978-82, 1982-86) y recuperada por Balaguer, su creador, durante la resaca de la década pérdida (1986-90, 1990-94), ha generado una situación de tránsito constante, de huida a ninguna parte, de la cual se deducen cuatro consecuencias básicas: 1) La transición política no ha estado acompañada de un cambio socioeconómico dirigido a reducir la pobreza en base a una redistribución equitativa de los ingresos. 2) La participación política ha estado limitada a la dinámica electoral, en la cual, el fuerte componente personalista se hace patente en las diferentes corrientes partidistas encabezadas por líderes carismáticos, la mayoría de los cuales desarrolla su poder mediante la compra de lealtades y el fraude electoral. 3) La escasa autolimitación de los gobiernos en el ejercicio de los poderes públicos y sus frágiles intentos por operar a través de instituciones responsables, no han superado la tradicional omnipresencia del poder Ejecutivo, típica de la deformación que del sistema presidencialista norteamericano han hecho las dictaduras latinoamericanas, entre cuyos efectos sobresalen: la debilidad del Poder Legislativo, la alarmante situación de postración del Poder Judicial, la inexistencia de carrera administrativa y la lenta agonía de la organización municipal. 4) La dificultad de traducir el mandato electoral en políticas eficaces, ha generado una crisis de gobernabilidad que se ha traducido en una situación de inestabilidad latente que se confunde con la propia naturaleza casi poliárquica del sistema político, pues, si bien no han aparecido amenazas sólidas de una total regresión autoritaria, resulta difícil avanzar hacia la consolidación de una democracia representativa.

En segundo lugar, resaltar la naturaleza gerontocrática de la cuasipoliarquía dominicana, cuyas características más notorias son: 1) La ausencia de un cambio generacional en el liderazgo político que permita la alternancia, cuya base institucional se encuentra en la reelección presidencial, el control de la Junta Central Electoral (JCE) y el Senado por el partido gobernante, y las alianzas electorales transitorias. Ello ha favorecido, por una parte, el liderazgo caudillista de Balaguer en el gobierno como continuador y transformador del autoritarismo trujillista (1960-62, 1966-78, 1986-96), salvo un breve período en la oposición (1978-86); y, por otra, la vigencia de un pluralismo de partidos moderado disfrazado, basado en la formación de alianzas electorales entre partidos mayoritarios y organizaciones minúsculas, de las que casi siempre resulta vencedora la coalición formada por el PR/PRSC. 2) La organización de los partidos en torno a liderazgos carismáticos que impiden la sucesión política y, en consecuencia, obstruyen su adaptabilidad institucional: el liderazgo carismático único de Balaguer en el movimientista Partido Reformista o Partido Reformista Social Cristiano (PR/PRSC) desde su fundación en 1963 y en perfecta cohabitación con su contemporáneo rival, Juan Bosch (1), en el liderazgo carismático puro del otrora marxista-leninista Partido de la Liberación Dominicana (PLD), desde su fundación en 1973 hasta su forzosa salida en junio de 1994. 3) La incapacidad de los líderes menos viejos para promover una verdadera transformación del sistema político que combata la ineficacia de las instituciones democráticas: Salvador Jorge Blanco y José Francisco Peña Gómez en el socialdemócrata PRD, y Jacobo Majluta en el conservador PRI desde 1990. 4) La escasa transformación de las instituciones heredadas del autoritarismo trujillista (la Iglesia católica, las Fuerzas Armadas, la organización laboral) y balaguerista (la Constitución de 1966, la Junta Central Electoral, la organización judicial), y el desinterés de los gobiernos democráticos por institucionalizar el sistema político mediante la creación de una ley de partidos, una profunda reforma del sistema electoral, la implementación de fórmulas de participación ciudadana que activen la sociedad civil en períodos no electorales (referendo, plebiscito) y mecanismos parlamentarios que cuestionen la acción gubernativa (mociones de censura o de confianza).

En tercer lugar, destacar el carácter delegativo de los gobiernos de Balaguer según los atributos neopatrimonialistas de lo que O'Donnell define como “democracia delegativa" (2), en la cual, las elecciones delegan en el Ejecutivo una autoridad que le permite hacer lo que quiera debido al escaso control que sobre sus errores ejercen otras ramas del Estado y a la limitada participación de los ciudadanos en períodos no electorales, que produce un movimientismo. Se trata de un tipo de democracia que puede ser duradera debido a su carácter mayoritario pero que no está consolidada o institucionalizada, pues si bien se cumplen algunos de los requisitos de Dahl para su definición de la poliarquía o democracia política (3), no se trata de una democracia representativa: el juego político se basa absolutamente en el factor suma cero, lo que permite al presidente elegido gobernar el país como le parezca conveniente, mientras los electores-delegantes esperan pasivos la celebración de un nuevo torneo electoral (4). A saber, el presidente Balaguer es la

(1) Balaguer nació el 1 de septiembre de 1907 y Bosch el 30 de junio de 1909.

(2) Guillermo O’Donnell: “Democracia Delegativa?” Cuadernos del CLAEH. N. 61 , pp. 5-20. Jonathan Hartlyn: Crisis Electoral (una vez más) y Regresión Autoritaria: Un análisis de las Elecciones de 1994 en la República Dominicana. En, M Alcántara e 1. Crespo (eds.): Los Límites de la Consolidación Democrática en América Latina. Ediciones Universidad de Salamanca, 1995.

(3) Robert Dahl: La Poliarquía. Participación y Oposición. Editorial Tecnos. Madrid, 1989.

(4) La seudodemocratización generada por la falsa creencia de que la elección concede al presidente un mandato mayoritario en virtud del cual sus planes de acción deben prevalecer sobre los del Congreso, es analizada por Dahl en los cambios sufridos por el presidencialismo norteamericano en los últimos dos siglos, cuyos efectos 
encarnación de la nación dominicana y como principal fiador del interés nacional está por encima de todo: de los partidos y de los intereses organizados (5). De ahí su diseño de la Constitución de 1966 con los ultra poderes que reconoce el artículo 55 al Presidente de la República, entre ellos, el manejo personalista de los fondos del Estado (6).

A principios de los años 90 , el déficit democrático que vivía la República Dominicana y las fracturas a corregir para que el país pudiese entrar en la fase de consolidación eran enormes. La tensión social era alta y se vivía una profunda crisis política agudizada por los polémicos resultados de las elecciones de 1990. La economía se contrajo en alrededor de un 5 por ciento, la inflación creció en 101 por ciento, el déficit del sector público aumentó en alrededor del 5 por ciento del PIB y crecieron las presiones hacia la balanza de pagos (7). Esos factores crearon cierta preocupación en la clase dirigente, que veía peligrar las relaciones exteriores en los inicios de un proceso de integración supranacional marcado por la entrada de la República Dominicana en el grupo caribeño ACP-Lomé de la Comunidad Europea, la permanencia en la Iniciativa para la Cuenca del Caribe (ICC II) y las expectativas de inserción en un mercado único continental encabezado por los Estados Unidos y Canadá, a partir del acceso de México al Tratado de Libre Comercio (TLC).

\section{Tabla II \\ RESULTADOS ELECTORALES A NIVEL PRESIDENCIAL DE LOS PRINCIPALES PARTIDOS Y COALICIONES, 1978-1994}

\begin{tabular}{lrrrrr}
\hline Elecciones & $\mathbf{1 9 7 8}$ & $\mathbf{1 9 8 2}$ & $\mathbf{1 9 8 6}$ & $\mathbf{1 9 9 0}$ & $\mathbf{1 9 9 4}$ \\
\cline { 2 - 6 } Total votos válidos. & & & & & \\
Porcentaje & 94.4 & 95.2 & 96.2 & 98.0 & 95.8 \\
\hline Partidos y coaliciones & 96.4 & 95.4 & 99.1 & 99.2 & 99.3 \\
PR/PRSC* & 42.4 & 36.6 & 40.5 & 33.5 & 41.9 \\
PR/PRSC y aliados & 42.6 & 38.8 & 41.5 & 35.1 & 42.3 \\
PRD & 52.0 & 46.7 & 33.5 & 23.0 & 39.4 \\
PRD y aliados & 52.7 & & 39.2 & 23.2 & 41.6 \\
PLD & 1.1 & 9.9 & 18.4 & 33.8 & 13.1 \\
PLD y aliados & & & & 33.9 & 13.1 \\
PRI & & & & 7.0 & 2.3 \\
\hline
\end{tabular}

* En 1984 el PR se convirtió en PRSC.

Los sectores políticos y económicos plantearon la necesidad de una reforma del Estado que promoviese la institu-

más importantes son: la pérdida de control popular y parlamentario sobre las decisiones presidenciales y la pérdida del peso del discurso ("fuerza intermediaria") en la relación entre el presidente y el pueblo. A juicio de Dahl, la solución a la seudodemocratización pasa por repensar la Constitución, imaginando una forma de gobierno más adecuada a los requisitos de la democracia. Robert A. Dahl: "El mito del mandato presidencial”. Cuadernos del CLAEH. N. ${ }^{\circ} 67,1993 / 3$, pp. 81-98.

(5) No es sorpresiva entonces la afirmación de Balaguer de que el secreto de su larga permanencia en el poder es cumplir siempre con su deber, mantener contacto con la población, trabajar las veinticuatro horas del día, no excederse nunca en el ejercicio de sus funciones y manejar con pulcritud los fondos del Estado. Véase, "Rep. Dominicana: 'Y sigue Balaguer'”. ABC. Madrid, 15 de junio de 1994.

(6) En una entrevista reciente Balaguer confirmó las sospechas sobre su manejo personal de las cuentas del Estado, al decir: "Todas las noches me traen las cuentas lo que entra y lo que sale. Sí, señor, punto por punto, lo mismo con los dólares que con los pesos dominicanos. Llevo una cuenta de dólares, que repaso todos los días como si fuera un tendero". Ibidem.

(7) Andrés Dauhajre, hijo: "La agenda económica pendiente". Rumbo. N. 16 , 17 de mayo de 1994, pp. 16-22. cionalización del sistema político y una mayor estabilidad de las estructuras económicas. Fue así como a finales de 1990 el presidente Balaguer puso en marcha un programa de estabilización de la economía bajo la supervisión del FMI, que permitió el inicio de un programa de reestructuración macroeconómica basado en una reforma arancelaria y financiera, la promulgación de un nuevo Código de Trabajo, un Código Tributario, y la puesta en marcha de un Plan Decenal de Educación. Eran los primeros pasos de un programa de "fortalecimiento institucional y modernización del Estado" que se completaría con la creación del servicio civil y la carrera administrativa, y la reestructuración del sistema electoral.

Los acuerdos entre el oficialista PRSC y los principales partidos de la oposición (PRD y PLD) promovieron una “actualización" parcial de la Ley Electoral 5884 de 1962 mediante dos nuevas leyes promulgadas en 1992 (Ley n. ${ }^{\circ}$ 8-92 y Ley n. $^{\circ}$ 12-92) con miras a las elecciones de 1994, para que la ausencia de conflictividad proporcionase la garantía de estabilidad necesaria para una mayor gobernabilidad del sistema político. A tal fin, se reformó el registro civil, el sistema de votación, las normas de legalización de los partidos políticos y la composición de la Junta Central Electoral (JCE).

La estabilización económica produjo algunos efectos positivos entre 1991 y 1993 (disminución de la inflación: 4.0 por ciento en 1991, 6.7 por ciento en 19.92 y 2.7 por ciento en 1993, aumento de la tasa de crecimiento: del 0,7 por ciento en 1991 al 7.9 por ciento en 1992 y al 3.0 por ciento en 1993 , y superávit del sector público: 0.1 por ciento del PIB a finales de 1991 y 1.6 por ciento a finales de 1992) (8) que beneficiaron a Balaguer en las elecciones de 1994, pero que empezaron a revertir a principios de aquel año al resurgir el desequilibrio interno creado por el creciente déficit fiscal, fruto de los excesivos gastos del gobierno, sobre todo en la campaña electoral. En efecto, sólo en los primeros tres meses de 1994 los gastos del sector público fueron de casi un 40 por ciento más que en el mismo período de 1993.

Por otra parte, el fracaso de la reforma electoral en momentos en que una parte importante del electorado reclamaba un relevo generacional que parecía impostergable incluso de cara a la comunidad internacional, tuvo como resultado la celebración de las elecciones más traumáticas que han tenido lugar en el país desde la transición de 1978 y el más fuerte clivaje sufrido desde entonces por la cuasipoliarquía dominicana, algunas de cuyas claves y prospectivas pretenden ser analizadas en este artículo en base a tres hipótesis: a) con la crisis electoral de 1994 la larga fase de incertidumbre e inestabilidad del sistema político empezó a tocar fondo; b) como consecuencia, la República Dominicana ha iniciado un camino lento pero imparable hacia la institucionalización democrática; c) la salida de Balaguer de la arena política no promoverá la muerte de su estilo de gobierno (decretista y movimientista), a menos que se produzca una verdadera reforma constitucional dirigida a eliminar el mito del mandato presidencial que confiere el carácter "cuasi” o "seudo" a la poliarquía dominicana.

(8) Andrés Dauhajre hijo, "Cómo mantener la estabilidad económica". Rumbo. N. ${ }^{\circ} 14,2$ de mayo de 1994 , pp. 17-18. 


\section{LA REELECCION DE BALAGUER EN 1994: ¿UN ULTIMO RETORNO?}

En el torneo electoral de 1994 los principales candidatos a la elección presidencial (presidente y vicepresidente) fueron: Joaquín Balaguer y Jacinto Peynado por el PRSC y aliados; José Francisco Peña Gómez y Fernando Alvarez Bogaert por el PRD y aliados; Juan Bosch y Leonel Fernández por el PLD y aliados; Jacobo Majluta y José Francisco Hernández por el PRI; Antonio Reynoso (padre Toño) y Ramón Vargas Mera por la coalición MIUCA-Nuevo Poder.

Como ha venido sucediendo desde las elecciones nacionales de 1986, el incumbente presidente Joaquín Balaguer (PRSC) fue reelegido una vez más por un estrecho margen de votos que fortaleció el denominado "síndrome del fraude", fruto de la desconfianza en los procesos de votación y en el control de la JCE por el partido gobernante. A saber, con una diferencia de votos de 2.3 por ciento Balaguer obtuvo el triunfo electoral frente a Jacobo Majluta (PRD) en 1986, con un 1.2 por ciento venció a su contemporáneo y más antiguo rival Juan Bosch (PLD) en 1990 y un 0.7 por ciento lo colocó por encima de José Francisco Peña Gómez (PRD) en las elecciones de 1994. Las irregularidades cometidas en los procesos electorales y los graves conflictos generados por unos resultados poco creíbles tienen su esencia en un sistema electoral basado en la mayoría simple a una sola vuelta que permite la formación de alianzas o coaliciones con carácter transitorio, y donde el máximo organismo electoral, la Junta Central Electoral (JCE), es una institución carente de autonomía y confianza fruto de su dependencia financiera del Ejecutivo y su control burocrático por el Senado, que es quien designa los jueces y demás miembros de la JCE.

Fue la sexta elección presidencial de Balaguer (casi nonagenario y ciego) desde su triunfo en las elecciones casi competitivas de 1966 y su séptimo retorno al poder desde su primera investidura en 1960 cuando, anunciado el ocaso de la dictadura trujillista por los efectos del fallido atentado del Servicio de Inteligencia Militar (SIM) contra el presidente venezolano Rómulo Betancourt (1959), Trujillo destituyó de la presidencia a su hermano Héctor Bienvenido e instaló en su lugar al entonces vicepresidente Balaguer, su fiel delfín, para contrarrestar la presión internacional. En consecuencia, a la muerte de Trujillo, Balaguer, que era el presidente de la República (1960-62), encabezó las primeras reformas políticas dirigidas a una apertura democrática "gradual" acorde con las exigencias del gobierno norteamericano.

En su última proclamación como candidato presidencial del PRSC en la Convención Extraordinaria del 6 de enero de 1994, Balaguer agradeció la confianza de su partido con un breve discurso, en el que dijo: "Aunque tengo razones poderosas, como en reiteradas veces lo he dicho, para no aceptar esta nominación, la acepto... con o contra mi voluntad, porque soy, desde que nací, un político desde los pies a la cabeza. Porque como tal me debo en primer término a mi país y, en segundo término, a mi partido, que en el curso de veinte años me ha llamado ocho veces a encabezar la boleta electoral en los grandes ciclos de la democracia dominicana “ (9).

(9) "Convención PRSC nomina a Balaguer". El Siglo, 7 de enero de 1994, p. 1.

\section{Los pactos preelectorales y el liderazgo extrasistémico}

Los principales partidos en los comicios de 1994 fueron los mismos que han dominado la arena política en el curso de las tres últimas décadas y, como en elecciones anteriores, endosaron la candidatura presidencial de sus respectivos líderes. El Partido Reformista Social Cristiano (PRSC) apoyó la candidatura del incumbente presidente Joaquín Balaguer, su único líder desde la fundación del originario Partido Reformista (PR) en 1963 y candidato presidencial permanente desde 1966. El Partido Revolucionario Dominicano ( $P R D$ ), fundado en La Habana en 1939 por Juan Bosch y Juan Isidro Jiménez Grullón durante el exilio trujillista y que ha jugado un rol determinante en la vida política dominicana desde principios de los años 60 , nominó por segunda vez a su máximo líder desde la salida de Bosch en 1973, José Francisco Peña Gómez, cuya primera presentación como candidato a la presidencia tuvo lugar en las elecciones de 1990. El Partido de la Liberación Dominica$n a(P L D)$ endosó la candidatura de Juan Bosch, único líder de los peledeístas desde la fundación del PLD en 1973 y candidato presidencial permanente desde la primera competición electoral de este partido en 1978 hasta su renuncia en junio de 1994. Entre los partidos minoritarios llamó la atención la candidatura presidencial del Padre Toño por el MIUCA-Nuevo Poder, por la excepcionalidad de ser un sacerdote católico (10) y un candidato extrasistémico con cierto atractivo entre los indecisos en unas elecciones cerradas y polarizadas.

\section{Tabla III \\ CÁMARA DE DIPUTADOS Y SENADO, 1978-1994}

\begin{tabular}{llrrrr}
\hline Período & Partidos & \multicolumn{2}{c}{ Diputados } & \multicolumn{2}{c}{ Senadores } \\
\cline { 3 - 6 } & & Escaños & $\begin{array}{c}\text { Votos } \\
\text { por ciento }\end{array}$ & Escaños & Votos \\
\hline $1978-82$ & PR & 43 & 47 & 16 & 59 \\
& PRD & 48 & 53 & 11 & 41 \\
$1982-86$ & PRSC & 63 & 42 & 10 & 37 \\
& PRD & 50 & 52 & 17 & 63 \\
& PLD & 7 & 6 & & \\
$1986-90$ & PRSC & 56 & 47 & 21 & 70 \\
& PRD & 48 & 40 & 7 & 23 \\
& PLD & 16 & 13 & 2 & 7 \\
$1990-94$ & PRSC & 41 & 34 & 16 & 53 \\
& PRD & 33 & 27 & 2 & 7 \\
& PLD & 44 & 37 & 12 & 40 \\
& PRI & 2 & 2 & & \\
$1994-98$ & PRSC & 50 & 42 & 14 & 47 \\
& PRD & 57 & 48 & 15 & 50 \\
& PLD & 13 & 11 & 1 & 3 \\
\hline
\end{tabular}

Las alianzas concertadas por los partidos mayoritarios con los pequeños partidos se convirtieron en la principal

(10) En la reciente historia política dominicana el último sacerdote en ocupar un cargo político fue Monseñor Eliseo Pérez Sánchez, miembro del Consejo de Estado formado en 1962 tras el asesinato de Trujillo. En las elecciones de 1962 el padre Miguel Angel Reynoso Sicard fue aspirante a la vicepresidencia. Amigo del Hogar. N. ${ }^{\circ}$ 552, septiembre de 1993, p. 1. Rumbo. N. ${ }^{\circ} 1,24$ de enero de 1994, p. 30. 
estrategia preelectoral de la oposición, una vez que Balaguer fue proclamado candidato a la presidencia por el PRSC. Era la octava vez que Balaguer se presentaba como candidato de los reformistas tras haber alimentado en los últimos cuatro años la incógnita sobre su posible rechazo a la candidatura presidencial. De modo que, convencidos de que el anciano presidente era un candidato difícil de vencer, los principales líderes de la oposición, encabezados por Peña Gómez, sustituyeron el habitual discurso triunfalista por una política de pactos preelectorales basada en el intercambio de votos por la nominación a cargos electivos, en la que se mezclaron las más variadas tendencias ideológicas y donde los enemigos más feroces se convirtieron en los mejores aliados. Se trataba, a fin de cuentas, de la puesta en marcha por la oposición de una estrategia tradicionalmente empleada por Balaguer para asegurarse el triunfo electoral .

En el PRD, los fracasados intentos de Peña Gómez por lograr una reconciliación con su antiguo rival Jacobo Majluta que condujera a una alianza con el PRI, motivaron la concertación de una serie de pactos cuyo punto de partida fue la alianza con Concertación Democrática (CD), minoritario partido de izquierdas liderado por el antiguo dirigente del movimiento antitrujillista 14 de Junio Rafael (Fafa) Taveras, el ex-peledeísta Vicente Bengoa y el antiguo dirigente del sindicato de profesores Rafael Santos. Pero la política de pactos del PRD alcanzó su climax con la oferta hecha por Peña Gómez a Fernando Alvarez Bogaert (antiguo delfín de Balaguer y jefe de la maquinaria electoral del conservador PRSC) para que fuera su compañero de boleta como candidato a la vicepresidencia, en momentos en que Alvarez Bogaert, convencido de que su larga espera por la herencia política de Balaguer había llegado a su fin, salía del PRSC acompañado de destacados dirigentes que venían apoyando su candidatura presidencial en un emergente proceso de faccionalización del PRSC que hasta la fecha no había preocupado en lo absoluto al único líder. La alianza entre Peña y Fernando aumentó considerablemente las expectativas de triunfo del PRD, e incluso antiguos compañeros de Bogaert estimaron que su salida del PRSC restaría unos 75,000 votos a Balaguer que mermarían su eventual reelección (11). A los buenos augurios de la alianza entre Peña y Fernando se sumó la popularidad de Milagros Ortiz Bosch (sobrina del ex-presidente Bosch) como candidata a senadora por el PRD para el Distrito Nacional, quien se había granjeado el apoyo público de prestigiosos ciudadanos no perredeístas (12). Y, si bien las irregularidades del proceso electoral impidieron conocer el número real de votos obtenidos por Peña Gómez y Bogaert, no sucedió así con Milagros Ortiz, que fue la candidata al Congreso más votada y es la única mujer que ocupa un escaño en el Senado en la actual legislatura (1994-1998).

Las alianzas pactadas por el PRD se conjugaron en la coalición "Acuerdo de Santo Domingo", en la que partici-

(11) "Dirigencia PRSC rechazaría nominen Majluta para la vice". El Siglo, 24 de enero de 1994 , p. 1.

(12) Peña Semanal: "Pese a boletas separadas analizan 'paquetes' de las legislaturas". Listín Diario, 20 de marzo de 1994. paron los siguientes partidos: Unidad Democrática (UD), fundado a mediados de los años 80 por el antiguo ex-peledeísta Antonio (Tonito) Abreu tras su excomunión por Bosch en 1978, aliado del PRD en 1986 y del PLD en 1990; Partido Popular Cristiano (PPC), liderado por Enedina Córdova y aliado del PRD por primera vez en 1986, es un antiguo brazo del Partido Revolucionario Social Cristiano desaparecido en 1984 tras su fusión con el Partido Reformista de Balaguer; Concertación Democrática (CD); el otrora marxista-leninista Partido de los Trabajadores Dominicanos (PTD), aliado del PRD desde 1990; y el Bloque Institucional Social Demócrata (BIS). Los más destacados en la campaña electoral fueron UD y PPC, fruto de su coalición inicial en la "alianza de acero" que presentó a Alvarez Bogaert como candidato a la presidencia.

En el PLD, los principales sublíderes expresaron la necesidad de formar una gran alianza como única forma de ganar "limpiamente" a Balaguer, fruto de la negativa experiencia de las elecciones de 1990 en las que el PLD venció al PRSC, pero los votos sumados al PRSC por sus pequeños aliados dieron el triunfo a Balaguer frente a Bosch. El fracaso electoral de 1990 había producido una profunda fractura en la cúpula, de cual el PLD no había logrado recuperarse y de cuya parálisis daba cuenta la nueva nominación del anciano líder y los obstáculos por él planteados para la concertación de alianzas. En efecto, el casi nonagenario Profesor Bosch mostró fuertes reticencias a pactar con sus antiguos discípulos Peña Gómez y Majluta, lo que impidió cualquier intento de alianza con el PRD o el PRI. Respetando la decisión del líder en un momento en que su enfermedad (demencia senil) había alcanzado niveles críticos, pero conscientes de que a Bosch le quedaba poco tiempo en la dirección del partido, la cúpula dirigente apoyó la candidatura del joven abogado Leonel Fernández (miembro de la corriente renovadora del Comité Central) para la nominación vicepresidencial, al tiempo que impulsó alianzas electorales con las más diversas corrientes políticas e ideológicas.

En un primer momento el PLD formó el "Frente Patriótico", dirigido a atraer de forma relativa a movimientos minoritarios, como el partido Alianza Social Dominicana: ASD (fundado a principios de los años 80 y liderado por el experredeísta José Rafael Abinader) y el Movimiento Cambio '94. Finalmente el PLD pactó con el minoritario partido conservador Fuerza Nacional Progresista (FNP) del abogado Marino Vinicio (Vincho) Castillo, que fue nominado candidato a senador por el Distrito Nacional. Vincho fue un fiel aliado de Balaguer durante su gobierno autoritario de los doce años (1966-78) y ha dirigido desde 1986 las acusaciones de corrupción de Balaguer contra el ex-presidente Salvador Jorge Blanco (1982-86), que dieron lugar al conocido juicio "del siglo" que mantiene sub judice a Jorge Blanco quien es, presumiblemente, el líder político más temido por Balaguer en su "infinita" carrera presidencial. A pesar de las profundas diferencias ideológicas entre Bosch (marxista-leninista) y Vincho (nacionalista-conservador), ambos comparten algunos puntos: el sólido antecedente legalista de Vincho (inicialmente conocido por sus trabajos en la elaboración de las leyes de Reforma Agraria de Balaguer en los años 70), su enemistad con Jorge Blanco, su rechazo al 
PRD, y su continua interpelación contra la corrupción. La alianza entre Bosch y Vincho fue un fracaso en términos electorales que no evitó su notable descenso y que devino en un proceso de "vinchización" del PLD, preludiado por el apoyo a la campaña antihaitiana de Balaguer y coronado con la concertación de acuerdos con el PRSC durante la crisis poselectoral que permitieron al PLD conseguir la presidencia de la Cámara de Diputados a pesar de ser minoría y una senaduría y una diputación por la provincia de Salcedo en base a un artificio legal de la JCE.

En el PRSC, la salida de Alvarez Bogaert planteó la posibilidad de una alianza entre Balaguer y Majluta (su más cercano heredero político en la oposición), que fue rechazada rápidamente por los principales sublíderes reformistas en su condición de fieles aspirantes a la sucesión de Balaguer desde la vicepresidencia, ante la eventual sustitución del presidente por el vicepresidente durante el nuevo período de gobierno, dado el inminente deterioro físico de Balaguer. Más aún, cuando se especulaba que el costo de la alianza de Balaguer con Majluta podría ser una vicepresidencia convertible en presidencia a partir de los dos años de gobierno, o sea, desde 1996. Condición que no se descartaba, bajo el supuesto de que lo que interesaba a Balaguer no era tanto concluir un séptimo mandato presidencial, sino ganarlo y preservarlo aunque sólo fuera hasta la mitad del cuatrienio (13). Pero, a pesar de haberse esfumado el rechazo de los viejos pinos a la candidatura vicepresidencial de Majluta por el PRSC, los acuerdos entre Balaguer y Majluta para formar alianza fracasaron. De modo que, consciente de la necesidad de reemplazar el liderazgo de Bogaert por un buen competidor, en febrero de 1994 Balaguer designó al empresario y popular ex-senador Jacinto Peynado como candidato a la vicepresidencia (14), en un clima intrapartidista caracterizado por la ausencia de conflictividad ya que, una vez más, el carácter movimientista del PRSC se hizo patente en el respaldo absoluto de los sublíderes reformistas al Movimiento "Lo Que Diga Balaguer". Al mismo tiempo, Balaguer se propuso reforzar sus apoyos en las zonas urbanas, sobre todo en el Distrito Nacional (Santo Domingo), donde eligió como candidato a senador a Yaqui Núñez del Risco, un popular presentador de televisión que empezó a servir al Presidente como extra-partido a raíz de su "sorpresiva" designación como Director del Aeropuerto Internacional de las Américas en el período 1990-1994, pero que no produjo el impacto esperado.

Finalmente, el PRSC se alió con pequeños partidos conservadores que le sumaron muy pocos votos y a los que, a excepción de sus viejos aliados (el PQD y el PDI con los que pactó dos diputaciones), Balaguer no ofreció importantes contrapartidas. Los aliados del PRSC fueron: Partido Quisqueyano Demócrata: PQD (del ex-general golpista Elías Wessin y Wessin, antiguo aliado de Balaguer que ha

(13) Peña Semanal: “Advierten costos políticos de alianzas". Listín Diario, 30 de enero de 1994 , p. 6

(14) Peynado ingresó en la actividad política a finales de los años 60 a través del Movimiento Acción Social Cristiana (MAS) liderado por Guido D'Alesandro y Caonabo Javier Castillo. Los inicios de su militancia en el PR se sitúan en 1982, cuando fue postulado por primera vez como candidato a senador por el Distrito $\mathrm{Na}$ cional. Su segunda victoria en la senaduría del D.N. en las elecciones de 1990 fue decisiva en la reválida del PRSC en el gobierno. mantenido un pacto permanente con el PRSC desde 1986), Partido Democrático Institucional: PDI (del ex-perredeísta Ismael Reyes Cruz, aliado desde 1990), Partido del Pueblo Dominicano: PPD (del ex-delfín de Bosch, Rafael Alburquerque, eminente abogado laboralista que tras haber sido excomulgado por su antiguo líder en 1986 fue capturado por Balaguer en 1990 para la Secretaría de Estado de Trabajo, donde dirigió la primera reforma hecha al Código Laboral vigente desde Trujillo), Movimiento de Conciliación Nacional (MCN) y Partido Renacentista Nacional (PRN).

Entre los partidos minoritarios que compitieron por la presidencia hubo sólo dos cuyos candidatos no se aliaron con los partidos mayoritarios: El Partido Revolucionario Independiente (PRI) y la coalición MIUCA (Movimiento Independencia, Unidad y Cambio)-Nuevo Poder.

El PRI surgió de la segunda fractura faccionalista del PRD a principios de los años 90 y nominó en 1994 por segunda vez a su fundador y único líder Jacobo Majluta, quien ha sido candidato presidencial en tres ocasiones: en 1986 por el PRD y en 1990 y 1994 por el PRI. A diferencia de lo ocurrido en las elecciones de 1990 en las que el 7 por ciento del PRI aumentó la volatilidad de los votos y la fragmentación del sistema al dividir el proceso en 4 partidos, la decisión de Majluta de hacer una oposición en solitario a Balaguer redujo sus apoyos al 2.3 por ciento de los votos en las elecciones de 1994.

El MIUCA-Nuevo Poder es una coalición formada por organizaciones populares y pequeños grupos de izquierda. El MIUCA emergió como movimiento popular a raíz de las movilizaciones sociales de mediados de los años 80 y estuvo liderado hasta diciembre de 1994 por Virtudes Alvarez. El movimiento Nuevo Poder fue fundado a principios de los años 90 por el Padre Toño, un cura católico cuya candidatura generó posiciones encontradas en la jerarquía eclesiástica y tras cuya nominación fue destituido. El advenedizo Antonio Reynoso Reynoso fue el candidato sorpresa en las elecciones de 1994 al presentarse como una alternativa al liderazgo tradicional, "una manera diferente de gobernar" (15). Influido por las tendencias populistas extrasistémicas que se presentaron como opciones personalizadas en América Latina (Fujimori en Perú, Collor de Melo en Brasil) y con un fuerte componente mesiánico en el Caribe (el padre Aristide en el vencino Haití), la propuesta del cura de La Vega (región del Cibao) apareció como innovadora en un país con una larga tradición partidista y, por tanto, carente de liderazgos extrasistémicos (16). Pero el propio carácter de movimiento social de esta organización hizo diluir rápidamente su efervescencia inicial, razón por la cual, aunque su empuje en las encuestas ( 2 por ciento entre abril y mayo de 1994) generó una cierta expectación entre los viejos par-

(15) "Padre Toño dice aflora 'síndrome' fraude electoral". Ultima Hora, 11 de abril de 1994, p. 16. Puth Herrera: "Perfiles de los candidatos presidenciales de 1994". Rumbo N. 16 (del 12 al 18 de mayo de 1994), p. 48.

(16) La inclinación del electorado hacia un liderazgo extrasistémico se puso de manifiesto en una encuesta de 1992, según la cual, el 30 por ciento se sentiría inclinado a votar por un candidato independiente. Este porcentaje es importante si se toma en cuenta que en el sistema de partidos dominicano, la existencia de un pluralismo moderado controlado por tres partidos mayoritarios determinó que el candidato presidencial que ganó las elecciones de 1990 obtuviese el 85 por ciento de los votos. Encuesta de Penn \& Schoen para el periódico Ultima Hora. Mayo de 1992, Santo Domingo, p. 36 
tidos carismáticos, en la proximidad de las elecciones su potencial quedó totalmente aniquilado (a principios de mayo a penas contaba con un 0.2 por ciento), alcanzando sólo el 0.75 por ciento de los votos.

\section{La campaña electoral y la crisis del vecino Haití}

La campaña electoral estuvo marcada por el resurgimiento del antihatianismo y el racismo en el marco de viejos odios nacionalistas que fueron capitalizados por Balaguer desde el PRSC y alimentados por el PLD, en una sucia campaña electoral contra Peña Gómez basada en su origen haitiano. La campaña publicitaria del PRSC hacía un llamado a los dominicanos para que defendieran "la nacionalidad" y conservaran "la paz, la libertad, el orden y el progreso", y acusaba al candidato del PRD de poner en juego la paz del país, practicar ritos satánicos, y ceder la soberanía dominicana al vecino Haití (17). El PLD, por su parte, difundió un vídeo en el que Peña Gómez aparece participando en supuestos actos satánicos, prácticas de vudú y brujería.

La reemergencia del antihaitianismo tuvo como principal estímulo las presiones del gobierno de los Estados Unidos para que Balaguer llevara a cabo un cierre total de la frontera dominico-haitiana, que permitiera viabilizar el embargo económico impuesto al gobierno militar de Raoul Cédras. Este factor afectó las conflictivas relaciones fronterizas entre ambos países, marcadas en la actualidad por los extraordinarios beneficios que reciben comerciantes y militares dominicanos del tráfico ilegal de mercancías (que hizo fracasar un convenio vigente entre 1979 y 1983) y las sanciones impuestas por los Estados Unidos al Estado dominicano a raíz de las denuncias de la OIT sobre la violación de los derechos de los braceros haitianos en los bateyes.

Balaguer basó su promesa electoral en la continuidad de su programa de obras públicas, reforzado por una fuerte campaña publicitaria en la que se llamaba a los dominicanos a votar masivamente por Balaguer, "un camino sin peligros, sin desviaciones, sin sorpresas desagradables", "un camino conocido" (18). Peña Gómez, por el contrario, criticó los excesivos gastos públicos de los gobiernos de Balaguer y fundó su promesa en programas sociales dirigidos a invertir "más en la gente". En un intento por desmarcarse del radicalismo ideológico que lo vinculó en el pasado con el socialismo y a fin de contrarrestar los ataques hechos en su contra por el PRSC, en el tradicional discurso de los principales candidatos ante la Cámara Americana de Comercio Peña intentó dar garantía a los norteamericanos de que su solidez ideológica centrista "sin un solo desvío", "ni hacia la ultra izquierda ni hacia la extrema derecha”, espantaría para siempre "el fantasma del continuismo y la injusticia social" y asentaría sobre "movimientos inconmovibles" un "Gobierno Compartido" (19). Bosch, por su parte, prometió una entrada en el siglo XXI "con la seguridad de

(17) Listín Diario, 10 de mayo de 1994, pp. 3D, 11.

(18) Listín Diario, 10 de mayo de 1994, p. 11

(19) "Peña Gómez explica a Cámara de Comercio Gobierno Dirigirá a Partir de Agosto de 1994". El Siglo, 14 de abril de 1994, p. 2-A. una vida próspera, con la esperanza de superar las condiciones de vida miserable" que imponen la pobreza, con justicia social y honestidad en el manejo de los fondos del Estado (20). El cuarto candidato, Majluta, mantuvo un discurso de corte nacionalista próximo al de Balaguer, en el que propuso "cambiar el rumbo de la República" mediante la ejecución de una política que asegurase y fortaleciese la independencia de la nación. El Padre Toño prometió "gobernar con el pueblo, gobernar con eficiencia, y gobernar sin robar" (21).

Otros aspectos destacados en la campaña electoral fueron: a) la violencia que enfrentó fundamentalmente a militantes del PRSC y del PRD (22); b) el alto costo de la campaña, considerada como la más cara en toda la historia electoral del país, fruto de los enormes gastos publicitarios hechos por los partidos (23); c) el elevado costo del montaje electoral que contó con una ayuda técnica y financiera de la Agencia Interamericana de Desarrollo (AID) de 21 millones de pesos y la asistencia financiera de la Fundación Internacional de Sistemas Electorales (IFES), dirigidas a la reorganización administrativa de la JCE y la unificación de la cédula de identidad y el registro electoral en un solo documento, a raíz de las reformas introducidas a la Ley Electoral en 1992 (24); d) la firma el 10 de mayo (a cuatro días de las elecciones) del "Pacto de Civilidad" propuesto por el PRD, mediante el cual, los principales líderes políticos (a excepción de Bosch) se comprometieron frente a la jerarquía católica y a destacados representantes de la sociedad civil a aplicar una serie de mecanismos dirigidos a garantizar la limpieza y competitividad de las elecciones y un clima contrario a la confrontación y a la violencia (25).

\section{El proceso de votación y la crisis poselectoral}

Los resultados electorales determinaron un retorno a la bipolarización, como en las elecciones de 1962, 1966, 1978 y 1982, pero esta vez entre coaliciones encabezadas por el PRD y el PRSC. En relación a los cuatro procesos electorales celebrados entre 1978 y 1990, el nivel de abstención en las elecciones de 1994 (13 por ciento) fue el más bajo y estuvo en parte motivado por las expectativas de un cambio generacional y la confianza en la reforma electoral.

A pesar de la reforma electoral y de los acuerdos informales sostenidos por los principales partidos (PRSC, PRD y PLD) para reducir la parcialización de los jueces de la Junta

(20) "Bosch dice gobiernos del PRSC y PRD no le han servido país". Listín Diario, 19 de abril de 1994, p. 5.

(21) P. Antonio Reynoso Reynoso (Toño), "Todavía grita la conciencia". El Nacional, 8 de Mayo de 1994.

(22) La campaña electoral dejó un saldo de 19 muertos, la mayoría de ellos en el curso de violentos enfrentamientos entre opositores y en accidentes de tráfico registrados durante las actividades proselitistas. "Altos gastos y violencia marcan proceso". Rumbo. N. 16,16 de mayo de 1994, p. 55.

(23) Según estimaciones ofrecidas por los partidos, los gastos ascendieron a cerca de 600 millones de pesos (USA\$ 480 millones), pero observadores independientes estimaron un monto mucho mayor. "Altos gastos y violencia marcan proceso", Rumbo. N. $.^{\circ} 16,16$ de mayo de 1994. "Partidos gastarán entre $\$ 200$ y $\$ 300$ millones", Ultima Hora, 13 de Febrero de 1994.

(24) "El más costoso montaje electoral". Rumbo. N. ${ }^{\circ} 16,16$ de mayo de 1994 pp. $44-45$.

(25) "El texto del Pacto de Civilidad". Listín Diario, 11 de mavo de 1994, p. 13. 
Tabla IV

REGISTRO DE ELECTORES

\section{Y PARTICIPACIÓN ELECTORAL. 1978-1994}

\begin{tabular}{lrrrrrrrrrr}
\hline & \multicolumn{1}{c}{$\mathbf{1 9 7 8}$} & por ciento & \multicolumn{1}{c}{$\mathbf{1 9 8 2}$} & por ciento & \multicolumn{1}{c}{ 1986 } & por ciento & 1990 & por ciento & 1994 & por ciento \\
\hline Registro electoral & 2.283 .784 & 100.00 & 2.601 .684 & 100.00 & 3.039 .347 & 100.00 & 3.275 .570 & 100.00 & 3.598 .328 & 100.00 \\
Abstenciones & 539.993 & 23,64 & 679.317 & 26.11 & 843.892 & 27.77 & 1.302 .539 & 39.77 & 451.618 & 12.55 \\
Votantes & 1.743 .791 & 76.36 & 1.922 .367 & 73.89 & 2.195 .455 & 72.23 & 1.973 .031 & 60.23 & 3.146 .710 & 87.45 \\
Votos nulos & 97.555 & 5.599 & 91.637 & 4.77 & 83.710 & 3.81 & 39.190 & 1.99 & 130.960 & 4.16 \\
Votos válidos & 1.646 .236 & 94.41 & 1.830 .730 & 95.23 & 2.111 .745 & 96.19 & 1.933 .841 & 98.01 & 3.015 .750 & 95.84 \\
\hline
\end{tabular}

Fuente: Datos oficiales de la Junta Electoral Central.

Central Electoral (JCE) con el gobernante PRSC, las notas dominantes fueron: las denuncias de fraude e irregularidades en el proceso de votación y de computación, la débil capacidad administrativa de la JCE y su notoria politización. El elemento innovador esta vez fue que, si bien los partidos presumieron una intención delictiva entre ellos (sobre todo en el oficialista PRSC) y respecto de la JCE, sus acusaciones estuvieron dirigidas a la JCE, a quien por primera vez le tocó demostrar si se cometieron o no irregularidades.

Las reformas de la Ley Electoral fracasaron por dos razones básicas. Por un lado, el nuevo sistema de votación mediante un documento unificado ("cédula de identidad y electoral") contenía grandes errores debido a su puesta en marcha en el breve período de dos años antes de la elección. Por otra parte, el nombramiento de los jueces de la JCE, que se hizo con dos años de retraso, siguió estando en manos del Senado controlado por el PRSC. De ahí que, a pesar del aumento en la composición del tribunal electoral de tres a cinco jueces, Balaguer ejerció su control sobre tres de ellos, incluyendo la designación del Juez Presidente, Manuel García Lizardo .

Las denuncias de fraude hechas por los partidos de la oposición se basaron fundamentalmente en la dislocación de electores (cambios en las listas de votantes) y la manipulación del cómputo por la JCE (26). Algunas de las irregularidades fueron confirmadas por los observadores internacionales (sobre todo la exclusión de un número importante de electores) y la intensa crisis poselectoral forzó la formación por la JCE de la "Comisión de Verificación” bajo la coordinación del Director General de Elecciones, Julio Brea Franco, quien comprobó la alteración del padrón electoral en miles de mesas y sugirió la anulación de la elección presidencial (27). No obstante, las elecciones no fueron anuladas y el 1 de agosto (a casi tres meses de la votación) el Presidente de la JCE proclamó el triunfo de Balaguer frente a Peña Gómez por 22,281 votos.

Las presiones norteamericanas en vísperas de la intervención militar en Haití, sirvieron de punta de lanza a Balaguer para denunciar la existencia de una supuesta "conjura" internacional dirigida a unir la República Dominicana y

(26) Estas irregularidades (unidas a la adulteración del carnet electoral, el doble sufragio y la compra del voto) han estado siempre presentes en las acusaciones de fraude, razón por la cual uno de los elementos acordados por los partidos en el "Pacto de Civilidad" fue solicitar la entrega por la JCE de las listas definitivas (padrón) de los electores el 11 de mayo, para cotejarlas con las listas de electores entregadas a los partidos, a fin de evitar el dislocamiento de votantes registrados en las mesas electorales. Véase, "El texto del Pacto de Civilidad...", ob. cit.

(27) Véase, "Otro fallo histórico". Rumbo. N. ${ }^{\circ} 28,8$ de agosto de 1994, p. 39
Haití. Pero las propuestas de negociación hechas por los principales partidos de la oposición en un ambiente internacional favorable a la solución de la crisis, introdujeron un elemento innovador que colocó el sistema político dominicano al borde de importantes cambios. Se trató de la firma del "Pacto por la Democracia", la víspera de la investidura oficial por la Asamblea Nacional del presidente Balaguer, por el que se acordó la realización de una serie de reformas institucionales, la mayoría de ellas fundamentales para la consolidación de la cuestionada democracia dominicana: a) celebrar nuevas elecciones presidenciales el 16 de noviembre de 1995; b) prohibir la reelección presidencial en dos períodos consecutivos; c) celebrar una segunda vuelta electoral si en la primera ninguno de los candidatos obtiene más del 50 por ciento del total de votos emitidos; d) establecer el sistema de votación de asambleas electorales en colegios cerrados; e) reformar el sistema judicial; f) modificar la Ley Electoral; g) conformar una nueva Junta Central Electoral; h) reorganizar las Oficialías del Estado Civil y el Registro Electoral; i) reconocer la doble nacionalidad, con el fin de facilitar la participación electoral de un gran número de dominicanos emigrantes (28).

A excepción de la violación por los parlamentarios del PRSC y el PLD del período fijado por el Pacto para la celebración de nuevas elecciones presidenciales (18 meses) mediante su ampliación a dos años, la reforma constitucional proclamada por la Asamblea Nacional el 14 de agosto de 1994 suscribió en su totalidad el contenido de dicho acuerdo.

\section{El preludio de las próximas elecciones presidenciales de 1996}

El actual período presidencial concluirá, por excepción, el 16 de agosto de 1996, una vez proclamado el candidato que resulte ganador en las elecciones presidenciales del 16 de mayo de 1996. La imposibilidad constitucional de Balaguer de promover su reelección es un hecho cierto. Ello a pesar del recurso de "inconstitucionalidad" incoado por el abogado reformista Ramón Pina Acevedo ante la Suprema Corte de Justicia, con el fin de prolongar el actual período de gobierno hasta 1998 (29).Y si se pueden considerar

(28) Véase, “JB, Peña, dirigentes políticos, eclesiásticos y empresariales firman Pacto por la Democracia”. El Siglo, 11 de agosto de 1994, p. 3.

(29) Juan Bolívar Díaz: "Los tiros contra la Constitución o preservar el poder de JB". Rumbo. N. ${ }^{\circ} 67,15$ de mayo de 1995 , p. 37. 
creíbles las promesas de Balaguer, su salida de la arena electoral es definitiva, pues en su último discurso ante la Asamblea Nacional el pasado 27 de febrero hizo un llamado a sus "compatriotas", "para que apoyen el Pacto por la Democracia". Tras señalar que la solución a la crisis política en que culminaron las elecciones de 1994 convierten el actual período en un régimen "casi de transición", Balaguer reconoció que su deber es dual: 1) ofrecer a la JCE las facilidades necesarias para que organice un proceso comicial que sirva, por su ejemplaridad, de modelo para el futuro de la democracia dominicana; 2) "preparar el gobierno para que las nuevas autoridades a ser electas en 1996 lo reciban en las condiciones más óptimas posibles" (30).

La andadura hacia las próximas elecciones comenzó a principios de 1995 , en medio de una generalizada sensación de anarquía promovida por la pérdida de credibilidad en las instituciones públicas, fruto de una corrupción rampante y un excesivo desorden burocrático encabezado por el anillo palaciego (31), que está llevando a la quiebra a las debilitadas empresas e instituciones del Estado, como es el caso de la Compañía Dominicana de Electricidad (CDE), el Consejo Estatal del Azúcar (CEA), la Corporación de Empresas Estatales (CORDE), y la Secretaría de Educación. La situación de desgobierno que vive actualmente el país ha paralizado las inversiones y agudizado el déficit fiscal. En su obsesión por terminar las obras públicas, Balaguer ha provocado un extremado aumento de la deuda interna mediante el incumplimiento de los compromisos contraídos con los suplidores de las instituciones públicas (el caso más patético es el de las Fuerzas Armadas) y las empresas constructoras. Como consecuencia del déficit fiscal, los salarios y el gasto social se mantienen en unos niveles muy bajos y los servicios públicos (transporte, electricidad, etc.) son cada vez más precarios, lo que está provocando continuas manifestaciones sociales y paros laborales (32).

A lo anterior se suma la crisis institucional creada por la negativa del PRSC a conocer en la primera legislatura del Senado la reforma a la Ley Electoral y la designación de los miembros del Consejo Nacional de la Magistratura (CNM) que, según la reforma constitucional surgida del "Pacto por la Democracia", será el encargado de elegir los jueces de la Suprema Corte de Justicia. Se trata de una estrategia política en la que el. PRSC intenta garantizarse una mayoría en el CNM (una institución que en su propio origen es deficiente porque favorece la confusión de poderes) y que al parecer cuenta con el apoyo del PLD que, con sus "ingenuas" salidas a los conflictos (como en los acuerdos poselectorales de 1994), más que soluciones parece buscar ventajas políticas que acabarán beneficiando a Balaguer. Es probable que en esta aparente componenda

(30) Juan Bolívar Díaz: "Balaguer en la ruta de la transición". Rumbo. N.. 57, 7 de marzo de 1995, p. 36.

(31) En una encuesta reciente el 71 por ciento de los dominicanos consideró que el grupo de funcionarios que rodea al presidente Balaguer es el que gobierna y un 53 por ciento consideró que el actual desorden administrativo es el mayor en la historia del país. Encuesta Rumbo-Gallup: "Los dominicanos creen que el 'anillo palaciego' gobierna”. Rumbo. N. ${ }^{\circ} 651$ de mavo de 1995, pp. 11-13.

(32) En la actualidad, el índice de analfabetismo en la República Dominicana es de un 26 por ciento, el 55 por ciento vive por debajo de la línea de la pobreza, hay 750.000 desempleados, 2.500 .000 personas carecen de servicios sanitarios y la mortalidad infantil es del 70 por mil. Hoy, 31 de mayo de 1995, p. 9. entre el PLD y el PRSC, el PLD (orientado por Vincho en su calidad de aliado) busque sacar ventaja del rechazo de los reformistas al proyecto de amnistía sometido por el PRD en el Senado con el fin de conseguir la libertad de Jorge Blanco. Algunos líderes de la oposición han coincidido en señalar que se trata de una conspiración contra las reformas democráticas, dirigida a crear una situación de inestabilidad insostenible que garantice la permanencia de Balaguer en el gobierno hasta 1998 (33).Ante la inestabilidad creada por el impasse en el Senado las jerarquías católica y empresarial, agrupadas en el "Grupo de Acción por la Democracia”, han hecho un llamado público para que se cumpla el mandato constitucional (34).

Expectantes ante el inminente relevo de Balaguer, los principales partidos de la oposición han designado ya sus candidatos a la presidencia. El PRD eligió nuevamente y sin grandes obstáculos a Peña Gómez para la candidatura presidencial, pero su decisión de ir acompañado de Alvarez Bogaert en la vicepresidencia generó posturas encontradas en la cúpula ante la posible sucesión de Peña Gómez en caso de producirse su desaparición física, fruto de las dudas creadas por su estado de salud tras haber sido sometido a una intervención quirúrgica en 1994. Para contrarrestar la lucha interna por su sucesión y sus efectos negativos de cara a las próximas elecciones, Peña combina una política partidista centralizada de corte autoritario con su asunción pública como predestinado social: "un hombre llamado por la historia y por el pueblo a encabezar un proceso de transformaciones sociales y políticas en la República Dominicana que marcarán un precedente de lo que hay que hacer en América Latina" en el próximo siglo (35).

El PLD eligió el pasado 23 de abril a Leonel Fernández (42 años) como candidato a la presidencia. Su holgada mayoría frente a los viejos pinos y el carácter democrático de la elección han generado importantes muestras de simpatía hacia su candidatura, sobre todo entre los jóvenes, que reconocen en él una bocanada de aire fresco en el proceso de democratización que vive el país. Percibido como "el que puede ganar" por las simpatías que despierta fuera del partido, Leonel ha sido calificado por algunos sectores de la oposición como un candidato con "vocación de concertación y visión histórica" (36).

El oficialista PRSC no ha elegido aún su candidato, pero la Comisión Ejecutiva del Directorio Central decidió el pasado 8 de mayo que el candidato a la presidencia será seleccionado mediante primarias abiertas en las que podrán participar todos los electores, ya que no se tendrá en cuenta la militancia partidista ni la simpatía política. Los reformistas esperan la participación de más de un millón de miembros del PRSC (37).Los principales candidatos son Jacinto Peynado (vicepresidente en funciones) y Carlos Morales

(33) "¿Está abocado el país a la violencia social?" Rumbo. N. 67, 15 de mayo de 1995 , pp. 8-12.

(34) Juan Bolívar Díaz: “¿Se acuerdan? En un año votaremos”. Rumbo. N. 68 , 22 de mayo de 1995, pp. 36-38.

(35) Véase, Peña Gómez: "Soy el último líder". Rumbo. N. 70,5 de junio de 1995 , p. 44

(36) Juan Bolívar Díaz: "El triunfo de Leonel Fernández y el nuevo liderazgo en el PLD". Rumbo. N. ${ }^{\circ} 65,1$ de mayo de 1995, pp. 38-39.

(37) "Elecciones abiertas para candidato de PRSC". Hoy, 9 de mayo de 1995, p.4. 
Troncoso (ex-vicepresidente). Peynado tiene como ventaja su acceso a los recursos del Ejecutivo y Morales se presenta como el candidato preferido por Balaguer (38).Algunos aspirantes vaticinan que esas primarias tendrán un carácter eminentemente democrático, otros sólo anhelan ser el candidato señalado por el dedo de Balaguer (39). Y mientras los reformistas discuten la fórmula a seguir para que las primarias no sean conflictivas, Balaguer, empeñado en su programa de obras públicas, ha rechazado la firma de un acuerdo con el FMI para evitar un control macroeconómico que impida el cruel proceso de endeudamiento al que está llevando el país.

Los pequeños partidos viven un proceso de fragmentación y recomposición, mientras intentan encontrar las brechas dejadas por otros para negociar futuras alianzas. En el PRI, la salida de su vicepresidente José Ovalle y su grupo tras sus diferencias con Majluta sobre la línea a seguir en las elecciones de 1996, ha dejado el campo abierto a Majluta para buscar alianzas partidistas y extrapartidistas que le permitan ganar el espacio que dejarán los balagueristas nostálgicos y la disidencia peledeísta. Majluta se presenta como un hombre con “experiencia de Estado" (a diferencia del candidato del PLD), con una edad aún no cercana a la vejez, con menos nivel de rechazo que Peña Gómez y coherente en sus planteamientos políticos (40). En los demás partidos minoritarios es notoria la ruptura de las alianzas concertadas por los conservadores
PDI y PQD con el PRSC, el resurgimiento del PNVC, la salida de Wessin del PQD y la unión de estos tres partidos en una alianza cuya representación en la Cámara de Diputados está siendo determinante en la mayoría simple necesaria para poder sesionar (60 escaños) y que coquetea con el PRD para que no tenga que pactar necesariamente con el PLD el conocimiento de sus proyectos de ley. En la izquierda, el sorpresivo Padre Toño ha formado el Partido Nueva Esperanza, surgido de su reciente fusión con Onda Democrática y el Movimiento por la Democracia. El MIUCA renovó su presidencia con María Teresa Cabrera y busca formar "un amplio frente político".

Hasta el momento, Peña Gómez (PRD) y Leonel Fernández (PLD) se perfilan como los candidatos favoritos para la elección presidencial de 1996, en un clima social favorable al respeto de las reglas democráticas, pero con la incertidumbre creada por un ambiente político en el que las componendas intra e inter-partidistas siguen primando sobre la voluntad general.

Finalmente, los cambios institucionales impulsados por la crisis poselectoral de 1994 y que motivaron la primera reforma a la Constitución no consensuada de 1966 anuncian ya el final del eterno retorno electoral de Balaguer, pero no han dado inicio aún a una nueva espiral política que destruya el estilo de gobierno decretista y movimientista por él creado, y promueva la transformación de la cuasipoliarquía gerontocrática y delegativa en una democracia representativa.

\section{RESUMEN}

Este artículo analiza los resultados de los comicios presidenciales de 1994, en los que Joaquín Balaguer obtuvo el triunfo por un estrecho margen. Previamente se identifican los principales rasgos específicos del sistema político dominicano y se describe el denso entramado de pactos preelectorales, así como las características de la campaña electoral, marcada también por la crisis política haitiana. Seguidamente se describe la situación política derivada del apretado resultado electoral, que culminó con la reforma constitucional aprobada el 14 de agosto de 1994. Por último, la autora analiza la evolución de las fuerzas políticas ante las elecciones presidenciales de agosto de 1996.

\section{ABSTRACT}

This article analyzes the results of the Presidential Elections of 1994, in which Joaquín Balaguer got the Presidency for a narrow gap. Previously, the author identify the main specific features of Dominican political system and describe the dense framework of preelectoral pacts and the characteristics of electoral campaign marked also by the Haitian political crisis. Later she describes the political situation which finished with the constitutional reform approved 14 August 1994. Finally, the author studies the evolution of political forces before the Presidential Elections of August 96.

(38) Los demás aspirantes a la sucesión de Balaguer son: Caonabo Javier Castillo, Ney Arias Lora, Víctor Gómez Bergés, Luis Toral, Donald Reid Cabral, Rafael Bello Andino, José Antonio Guzmán, Joaquín Ricardo, Angel Lockward, Federico Antún Batlle, Juan Aristides Taveras Guzmán y Ramón Pérez Martín.

(39) Un 53 por ciento de los dominicanos cree que el candidato presidencial será, como reza una campaña publicitaria, "el que diga Balaguer". Encuesta Rumbo-Gallup: "La gente cree dedo de Balaguer señalará candidato PRSC". Rumbo. N." 66, 8 de mayo de 1995, p. 47.

(40) Véase, "Majluta: su clave será la unidad fuera de los partidos". Rumbo. N. 71 , 12 de junio de 1995, pp. 42-43. 